\title{
THE EFFECTS OF QUALITY LIFE MODELS ON THE DEVELOPMENT OF RESEARCH AND PRACTICE IN THE FIELD OF DOWN SYNDROME
}

\author{
Roy I Brown Professor and Dean \\ School of Special Education and Disability Studies \\ Flinders University of South Australia
}

\begin{abstract}
The paper summarises the development of recent developments in relation to Quality of Life models in the field of intellectual disability. The information is applied to the development of professional practice and research. As examples, a series of research studies on Down syndrome are briefly described.
\end{abstract}

Keywords: $\quad$ Down syndrome, Quality of Life, well-being

\section{Research and Quality of Life}

It is only in the last few years that major studies have been undertaken which relate to intervention in the field of quality of life and intellectual

disability. Examples are to be found in the work by Renwick, Brown and Nagler (1996) and in Brown, Bayer and Brown (1992). Quality of life is seen as the development of wellbeing. Felce and Perry (1997) define five clear areas of wellbeing, which set the theme for a major understanding of quality of life. These are:

Physical Wellbeing Material Wellbeing Social Wellbeing Emotional Wellbeing Productive Wellbeing

Quality of life is also seen as an holistic role in the life of each individual. Such perceptions are important, not only from the consumer's point of view, but from those of other stakeholders, such as parents, spouses and the various professionals involved. The wide range of components within the quality of life model raise important questions about research and practice.

\section{Quality of Life Measures}

Cummins (1995), in his review of quality of life measures, mentions over 200 such scales developed to measure different components of quality of life. Both quantitative and qualitative approaches are seen to be relevant, and subjective and objective factors are important. Qualitative studies are particularly relevant at the initial stages in defining a new field.

Figure 1

THE HOLISTIC NATURE OF QUALITY OF LIFE

LEISURE (8)
EDUCATION (7)
EMPLOYMENT (6)
TRAINING (5)
SOCIAL SKILLS (4)
SEXUALITY (3)
PHYSICAL HEALTH (2)
MENTAL HEALTH (1)

RECREATION (9) SPORT (10)

FRIENDSHIP (11)

NUTRITION (12)

HOME LIVING (13)

COMMUNITY INITIATIVE \& LIVING (14) MARRIAGE \& PARTNERSHIPS (15)

FAMILY (16) Indeed, if we look at the harder sciences, we find that naturalistic enquiry has preceded calibrated measurement. This, for example, is true in the development of biological concepts such as evolution. It is also true in relation to astronomy. In both these 
areas, observation and careful recording precede to more specific, and, ever more precise, measurement. Quality of life research, then, particularly lends itself to a broad base of research methodology. Research is sometimes seen as synonymous with experimental methodology. This is inappropriate. Other methodologies, such as ethnographic research, discourse analysis, and phenomenology represent approaches which are clearly described in the literature and are effective in this domain. Their use appears to solve a wide number of problems and enables us to conceptualise the nature of disability and our responses to it in rather different ways from those we have normally associated with this field.

\section{Perceptual Measures}

Another important component is the role of consumer perception. Traditionally, perceptual measures have been seen as subjective, and have largely been disregarded in terms of science. Yet this is an extraordinary omission for one only has to look at the traditional sciences to realise that perception has played a dominant role in the development and formulation of theory and the development of precise measuring tools.

Unfortunately, what individuals say about their understanding of choice, how they perceive dimensions of life (e.g. how they perceive their carers, and professionals) are regarded as subjective responses and often with suspicion. My view is that they are perceptual responses and can be taken to be the way individuals, at particular points in time, decide to encode their understanding of what is happening. Such perceptions are capable of meeting quite traditional standards of objectivity. For example, they may be checked for reliability and, within our own results, test/retest reliabilities have ranged from about 0.5 to 0.9 (Brown \& Bayer, 1992). This should be regarded as respectable.

In terms of validity, we sometimes find low correlations between the perceptions of people with Down syndrome, their parents and also professionals. But there is an interesting reason for this. Continued intervention will often see the emergence of closer agreement between

participants, relatives and professionals, and we are now using this as a marker of progress. It can also be an effective tool in carrying out counselling between members of families and professionals as we discuss with them the different perceptions and help to explain why these exist. The large differences in perception between individuals and their families is most marked in areas relating to emotional concerns and issues concerning selfimage. The Down Syndrome research of Brown (1991) shows this clearly.
I am arguing that the omission of perceptual data, whether or not regarded as objective or subjective, does a grave disservice to our understanding of the field of disability, a view underscored by Andrews (1974) who noted that individuals respond to what they perceive, rather than objective realities. What individuals feel about themselves is likely to be a major determinant of behaviour.

The results we have obtained from research on quality of life (Brown, Brown \& Bayer, 1994) is marked by an enormous range of variability of behaviour; variability that increases as individuals undergo involvement in quality of life models. We found that individuals, including those with Down syndrome, who did not take part in, for one reason or another, quality of life interventions (that is, choice over type of activity, place of activity and the individual who is structuring, applying the activity, or supporting the consumer) did not improve significantly compared with our quality of life intervention group. One explanation is that when parents do not believe an individual can benefit from behavioural and social intervention, he or she is unlikely to make progress. Why parents think progress is or is not possible is complex, but it is in the interests of the child that the parents have a positive (but not unrealistic) view of potential progress.

Quality of life intervention amongst persons with Down Syndrome resulted in maintaining self image (i.e. how I see myself getting on in a number of areas) compared with non-intervention groups whose score tended to decline. This was different from other persons with intellectual disability and may have been associated with the presence of an earlier ageing process in persons with Down Syndrome. The same effect was noted in recreation and leisure activities where the intervention group held their performance while those without quality of life intervention declined (Brown, 1991). This raises the interesting hypothesis that quality of life intervention around recreation and lifestyle may help to withstand the early ageing process. Leisure and recreation may reduce decline.

\section{Experimental Versus Other Types of Research}

Much research to date has been forced into a quasi-experimental methodology where experimental and control groups have been contrasted in terms of the efficacy of the presence or absence of an independent variable. The quality of life model suggests that there are a range of percepetual measures which may represent critical independent variables which may be more relevant than intelligence or chronological age. It is these 
variables we may need to control if we are to carry out experimental studies. Until we do this, error factors are likely to be large and many experimental studies fruitless for, without such control, variability in performance is likely to swamp differences between groups. We are in danger of finding statistical insignificance because the perceptual views of the participants are also functioning as causal independent variables. Of course, all of the above argues for looking at the descriptors of individuals in terms of perception.

\section{Implications for Future Research}

In a number of studies we are attempting to apply some of the quality of life concepts discussed above to research in Down Syndrome.

I) One study concerns issues of awareness and imagery (Brown \& Bullitis). Some may refer to this as consciousness. If we take the quality of life argument seriously, and recognise that we are dealing increasingly with personal perception, we are inevitably drawn to issues surrounding whether individuals perceive things clearly and whether they go through meta-cognitive processes in regard to this awareness. Some preliminary results on this research suggests that people with Down syndrome often have very vivid visual mental imagery and use this effectively in humour, relationships, drama and art. Cautiously, I suggest this is more vivid than in many other persons with intellectual disability without Down Syndrome. If this is correct it may be relevant to educational, social, community living and employment situations, and could play a role in education training and rehabilitation.

\section{2) A second study relates to the information} provided to mothers of new-born Down Syndrome children by health professionals (Kyrkou, Brown \& Thornley). We believe that this may be not only important for the mother, but critical for how the child develops later. Negative views about Down syndrome are still provided to mothers at the birth of their child. These views are likely to influence the perceptions, attitudes and motivation of the parents. Yet earlier I demonstrated that acceptance of such views could well influence the way intervention is viewed, including the self image of the child, which is seen as crucial in many quality of life studies. We wish to document these early views passed to parents, particularly mothers, and suggest ways in which more positive, but not unrealistic views, can be presented. Our aim is to present this material in booklet form to alert parents and professionals to these concerns.

3) A third study examines leisure, recreation and friendships in adolescents and young adults with Down syndrome (Bottroff, Duffield \& Brown).
Leisure and recreational pursuits can contribute significantly to a person's holistic view of health, stress reduction, and cognitive stimulation. Such pursuits also offer opportunities to increase social interactions and develop friendships. Our aim is to investigate the nature and relationship between individual's participation in leisure and recreation pursuits and acquisition of friends. We are Investigating their understanding of concepts associated with friendships and pursuing their understanding of personal perceptions of these domains in terms of increasing involvement and activity in social life. All of this has direct relevance to life span issues including support as individual's age and their ability to form lasting partnerships for the issue of isolation in later life is a critical one (see Brown 1995).

4) A fourth study, on aspects of wellbeing in employment for people with Down syndrome (Grantley, Thornley and Brown) is concerned with employment within open market situations through individualised placement. The information gained from quality of life studies argues for the placement of adolescents and adults in individualised and matched job placements rather than depending on traditional group situations.

This individual support takes into account choices, personal development and individual variability and provides opportunities to apply support in holistic aspects of living with a view to enhancing employment activity (eg support at home to get ready for going to work, nutritional intervention to enhance work performance, activities at home and community which will support the employment process).

\section{Concluding Comments}

This paper illustrates some of the changes in research and practice exemplified by quality of life studies. The critical relevance of personal perception is discussed. Finally, some examples of research development in Down Syndrome involving quality of life concepts were briefly described, indicating the way such studies can impact the aims, direction, structure and interpretation of research and practice.

\section{Footnote}

This paper was prepared for the 6th World Congress, Madrid, at the same time as a presentation to the 20th Anniversary of Down Syndrome Research at the Schonell Centre, University of Queensland, Australia. These papers share some common content. 


\section{References}

Andrews, F.M. (1974) Social indicators of perceived life quality. Social Indicators Research, 1, 279-299.

Brown, R. I. and Bayer, M. B. (1992) Rehabilitation Questionnaire and Manual: A Personal Guide to the Indiuidual's Quality of Life. Toronto: Captus Press.

Brown, R.I. (1994) Down syndrome and quality of life: some challenges for future practice. Down's Syndrome Research and Practice. The Journal of the Sarah Duffen Centre, 2(1), 19-30.

Brown, R.I. (1995) Social Life, Dating, and Marriage in L. Nadel \& D. Rosenthal (Eds.) Down Syndrome: Living and Learning in the Community. New York: Wiley-Liss.

Brown, R. I. (1997) Quality of life: the development of an idea. In R. I. Brown, (Ed.) Quality of Life for People with Disabilities: Models, Research and Practice. Cheltenham: Stanley Thornes.

Brown, R.I., Bayer, M., \& Brown, P.M.. (1992). Empowerment and Developmental Handicaps: Choices and Quality of Life. Toronto, Ontario, Captus Press and London: Chapman and Hall.

Brown, R.I., Brown, P.M., \& Bayer, M. B. (1994). A Quality of Life Model: New Challenges Arising from a Six Year Study. In D. Goode (Ed.). Quality of Life for Persons with Disabilities, International Perspectiues and Issues. Cambridge: Brookline Books.

Cummins, R. A. (1995). Directory of Instruments to Measure Quality of life and Cognate Areas. Deakin University: Burwood, Victoria, Australia.

Felce, D. \& Perry, J. (1997). Quality of life: the scope of the term and its breadth of measurement in Roy I. Brown (Ed.) Quality of Life for People with Disabilities: Models, Research and Practice. London: Stanley Thornes.

Renwick, R., Brown, I. \& Nagler, M. (1996). Quality of Life in Health Promotion and Rehabilitation: Conceptual Approaches, Issues, and Applications. Thousand Oaks, CA: Sage.

Taylor, S. J. (1994). In Support of Research on Quality of Life, but against QOL. In D. Goode (Ed.) Quality of Life for Persons with Disabilities: International Perspectiues and Issues. Cambridge, MA: Brookline. 